\title{
Detecting Warming Hiatus Periods in CMIP5 Climate Model Projections
}

\author{
Tony W. Li ${ }^{1}$ and Noel C. Baker ${ }^{2}$ \\ ${ }^{1}$ Cornell University, Ithaca, NY 14850, USA \\ ${ }^{2}$ NASA Langley Research Center, Hampton, VA 23681, USA \\ Correspondence should be addressed to Tony W. Li; tw158@cornell.edu and Noel C. Baker; ncbaker@asu.edu
}

Received 12 February 2016; Revised 5 May 2016; Accepted 15 June 2016

Academic Editor: Prodromos Zanis

Copyright ( 2016 T. W. Li and N. C. Baker. This is an open access article distributed under the Creative Commons Attribution License, which permits unrestricted use, distribution, and reproduction in any medium, provided the original work is properly cited.

\begin{abstract}
The observed slow-down in the global-mean surface temperature (GST) warming from 1998 to 2012 has been called a "warming hiatus." Certain climate models, operating under experiments which simulate warming by increasing radiative forcing, have been shown to reproduce periods which resemble the observed hiatus. The present study provides a comprehensive analysis of 38 CMIP5 climate models to provide further evidence that models produce warming hiatus periods during warming experiments. GST rates are simulated in each model for the 21st century using two experiments: a moderate warming scenario (RCP4.5) and high-end scenario (RCP8.5). Warming hiatus periods are identified in model simulations by detecting (1) $\geq 15$-year periods lacking a statistically meaningful trend and (2) rapid changes in the GST rate which resemble the observed 1998-2012 hiatus. Under the RCP4.5 experiment, all tested models produce warming hiatus periods. However, once radiative forcing exceeds $5 \mathrm{~W} / \mathrm{m}^{2}-$ about $2^{\circ} \mathrm{C}$ GST increase-as simulated in the RCP8.5 experiment after 2050, nearly all models produce only positive warming trends. All models show evidence of rapid changes in the GST rate resembling the observed hiatus, showing that the climate variations associated with warming hiatus periods are still evident in the models, even under accelerated warming conditions.
\end{abstract}

\section{Introduction}

The global-mean surface temperature (hereafter GST) rate increase during recent years has slowed down relative to the rates for the second half of the 20th century; according to the Intergovernmental Panel on Climate Change (IPCC) Fifth Assessment Report (AR5; [1]), the GST trend between the years 1998-2012 is only about one-third to one-half of the trend from 1951 to 2012, with a GST rate decline from about $.13^{\circ} \mathrm{C} /$ decade to $.07^{\circ} \mathrm{C} /$ decade during the warming hiatus period.

Previous papers examining the recent hiatus period have proposed a variety of causes for the decline in the GST rate, although no consensus has been reached. Some authors argue that the hiatus resulted from a decrease in atmospheric radiative forcing. Kaufmann et al. [2] show that the increase in greenhouse gases from 1998 to 2008 was partially offset by an increase in Chinese coal consumption resulting in higher sulfur aerosol concentrations which have a cooling effect. Solomon et al. [3] suggest that decreases in stratospheric water vapor observed after the year 2000 contributed substantially to the slow-down in warming. Additionally, increases in the background level of stratospheric aerosols since the year 2000 have been proposed as a possible cause of the slow-down by Solomon et al. [4]. Reduced solar activity during this period may have also had a significant effect on the GST [5].

Other papers suggest that the slow-down in GST warming is due to Earth's natural variability suppressing the anthropogenic signal. For instance, Trenberth and Fasullo [6] propose that the slow-down is due to the Pacific Decadal Oscillation (PDO) switching from the positive phase to the negative phase around 1998, causing more heat content to be stored in the deep oceans and consequently leading to cooling at the surface. Chen and Tung [7] also propose that the slow-down in warming is caused by increased ocean heat sequestration due to natural variability and argue that the Atlantic and Southern Oceans are responsible for the majority 
of this sequestration. Additionally, Vialard [8] suggests that natural climate variability has caused more heat to enter the Pacific Ocean, which was then transferred to the Indian Ocean through general ocean circulation.

Several studies test the hypothesis of whether observed warming hiatus periods can be explained by natural variability by examining GST records simulated by climate models. Meehl et al. [9] use simulated output from the Community Climate System Model version 4 (CCSM4) and find several 10-15-year periods with zero warming trend, noting an increase in ocean heat content below 750 meters depth and a decrease in the $0-300$-meter depth range during these periods. Furthermore, Easterling and Wehner [10] examine decadal trends in 21st-century projections of Coupled Model Intercomparison Project Phase 3 (CMIP3) models and find that, even under experiments with accelerated surface warming, there is at least a $5 \%$ chance of observing a zero or negative decadal trend throughout the century. Recently, Roberts et al. [11] quantified the probability of 10year warming hiatus periods occurring in 21 models of the CMIP Phase 5 (CMIP5, [12]) model ensemble using presentday and RCP4.5 experiments. These studies determined that models are able to produce hiatus periods under present-day conditions as well as under accelerated warming conditions.

The present study differs from previous work in several ways. Previous studies often define hiatus periods as those with a zero or negative GST trend or as periods of 10 or more years; in contrast, the present analysis looks for 15 -year or longer periods with no statistically meaningful positive trend. This description of a hiatus period is most similar to the IPCC AR5 description that the trend for the 15-year period 1998-2012, although positive, was not statistically significant [1]. Shortening the length of the time period considered would increase the possibility of detecting warming hiatus periods due to short-term variations, as shown by Roberts et al. [11]. Additionally, the analyses are performed for the first time using all available global climate model simulations from CMIP5 on output data from two Representative Concentration Pathway (RCP) experiments: a moderate warming scenario (RCP4.5) and a highend accelerated warming scenario (RCP8.5). The statistical analyses are performed on the simulated 21st-century GST anomaly projections from 38 different climate models, and the results using each RCP experiment are compared to better understand the experimental conditions under which climate models are able to simulate hiatus periods. By identifying periods which more closely resemble the observed hiatus through both a lack of a statistically meaningful trend and associated GST rate changes, performed on output from two different warming experiments, the present study provides an updated comprehensive analysis to better characterize model ability to simulate hiatus periods.

\section{Data and Methods}

This study uses statistical tests to compare the observed GST anomaly data record with model-simulated records and detect evidence of warming hiatus periods. Two different statistical methods are used to identify hiatus periods: (1) a type of statistical significance test for data trends-called a "statistical meaningfulness" test [13] —is performed to find periods in model data records with no statistically meaningful GST warming or cooling and (2) large, rapid changes in the GST rate are identified in the model data records which are consistent with variations observed in the recent hiatus.

2.1. Observational and Model Data. Observational surface temperature data are taken from the Goddard Institute for Space Studies Surface Temperature Analysis (GISTEMP, [14]). The data consists of monthly temperature anomalies, calculated relative to the 1951-1980 mean baseline period, from January 1880 to May 2015 on a 2-degree latitude by 2degree longitude grid.

Model-simulated surface temperature data records are taken from the 38 CMIP5 models listed in Table 1. The CMIP5 experimental design provides standard conditions and forcing parameters for climate model experiments and archives the simulation data produced by various research centers around the world, making it ideal for comparing results from multiple independent models. The RCP experiments test climate responses based on scenarios of different socioeconomic conditions that estimate future anthropogenic greenhouse gas emission concentrations and a corresponding atmospheric radiative forcing increase (further details can be found in [12]). The two RCP experiments used in this project are RCP 4.5 (in which anthropogenic emissions peak around 2040 and then decline) and RCP 8.5 (in which emissions continue to rise throughout the century) which assume increases in radiative forcing equal to 4.5 Watts per meters ${ }^{2}\left(\mathrm{~W} / \mathrm{m}^{2}\right)$ and $8.5 \mathrm{~W} / \mathrm{m}^{2}$ by 2100 , respectively, relative to preindustrial conditions. The experiment simulations output surface skin temperature in monthly time steps for the years 2006-2100. In order to compare model data records with observations, the surface temperature values are converted to anomalies for each model by subtracting a baseline climatology from the record, computed from the period 1951-1980 in the CMIP5 Historical experiment simulations. Only the first ensemble member (labeled as rlilp1) for each model is analyzed since many models only provide one member.

2.2. Detecting Hiatus Periods. A statistical test for identifying hiatus periods is performed on both the GISS observed GST anomaly record and the model-simulated data records from the RCP 4.5 and 8.5 experiments. A hiatus period is defined for the purposes of this study as a 15-year or longer period in the GST data record which lacks a statistically meaningful trend; this definition is consistent with the IPCC AR5 analysis of the 1998-2012 hiatus period [1]. The test used in this study determines the statistical meaningfulness of trends as proposed by Bryhn and Dimberg [13] by checking for both statistical significance at the 95\% confidence level and a high correlation between the trend line and the data (using a coefficient of determination value $r^{2} \geq 0.65$ ).

The statistical meaningfulness test is first used on the GST anomaly record from GISTEMP. Figure 1 shows the observed monthly GST anomaly from the 1951-1980 mean. The statistical meaningfulness test is performed on each 
TABLE 1: The 38 CMIP5 models analyzed in this study, listed with their respective research institutions [12].

Research institution

CSIRO (Commonwealth Scientific and Industrial Research Organisation, Australia) and Bureau of Meteorology

Beijing Climate Center, China Meteorological Administration

College of Global Change and Earth System

Science, Beijing Normal University

Canadian Centre for Climate Modelling and Analysis

National Center for Atmospheric Research

National Center for Atmospheric Research Community Earth System Model Contributors

Centro Euro-Mediterraneo per I Cambiamenti Climatici

Centre National de Recherches Meteorologiques/Centre Europeen de Recherche et Formation Avancees en

Calcul Scientifique

Commonwealth Scientific and Industrial Research Organisation in collaboration with the Queensland Climate Change Centre of Excellence

LASG, Institute of Atmospheric Physics, Chinese Academy of Sciences, and CESS, Tsinghua University

The First Institute of Oceanography, SOA

NOAA Geophysical Fluid Dynamics Laboratory

NASA Goddard Institute for Space Studies

National Institute of Meteorological Research/Korea

Meteorological Administration

Met Office Hadley Centre (additional HadGEM2-ES realizations contributed by Instituto Nacional de Pesquisas

Espaciais)

Institute for Numerical Mathematics

Institute Pierre-Simon Laplace

Atmosphere and Ocean Research Institute (The University of Tokyo), National Institute for Environmental Studies, and Japan Agency for Marine-Earth Science and Technology

Max-Planck-Institut für Meteorologie

Meteorological Research Institute

Norwegian Climate Centre
Model

ACCESS1.0

ACCESS1.3

BCC-CSM1.1

BCC-CSM1.1.m

BNU-ESM

CanESM2

CCSM4

CESM1-BGC

CESM1-CAM5

CESM1-WACCM

CMCC-CM

CMCC-CMS

CNRM-CM5

CSIRO-Mk3.6.0

FGOALS-g2

FIO-ESM

GFDL-CM3

GFDL-ESM2G

GFDL-ESM2M

GISS-E2-H

GISS-E2-H-CC

GISS-E2-R

GISS-E2-R-CC

HadGEM2-AO

HadGEM2-CC

HadGEM2-ES

INM-CM4

IPSL-CM5A-LR

IPSL-CM5A-MR

IPSL-CM5B-LR

MIROC5

MIROC-ESM

MIROC-ESM-CHEM

MPI-ESM-LR

MPI-ESM-MR

MRI-CGCM3

NorESM1-M

NorESM1-ME 15-year period, moving by monthly time steps. For each period that had a statistically meaningful trend, the month corresponding to the end of that period was marked red (for a positive trend) or blue (for a negative trend), and periods lacking a statistically meaningful trend are marked black. The corresponding statistically meaningful positive (red) or negative (blue) trend lines are overlaid on the figure. While the GST record contains several periods with a cooling trend in the early and mid-20th century, the majority of 15-year trend periods after 1900 exhibit a statistically meaningful warming trend, especially toward the latter half of the 20th century. The months between 2012 and 2014 are not colored 


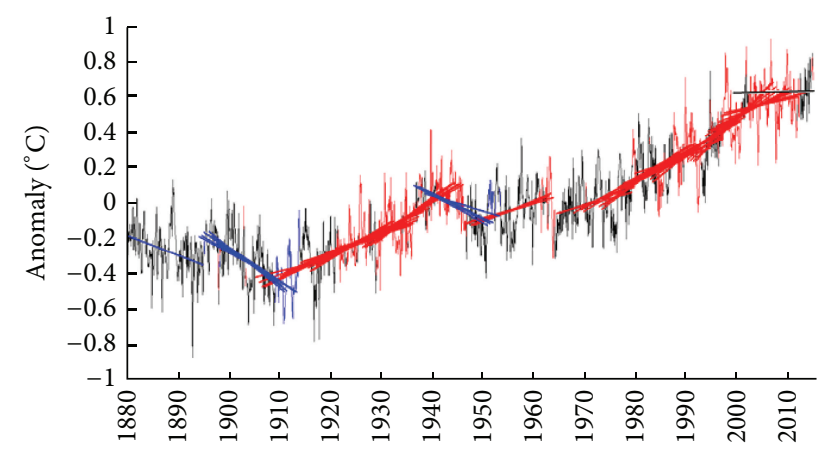

FIGURE 1: Observed monthly global-mean surface temperature (GST) anomalies from GISTEMP for the period 1880-2015. The months at the end of 15 -year periods with statistically meaningful trends are marked red for a positive trend and blue for a negative trend (overlaid with corresponding trend lines); black indicates no statistically meaningful trend for the prior 15 -year period. The overlaid black trend line indicates the 1998-2012 observed warming hiatus.

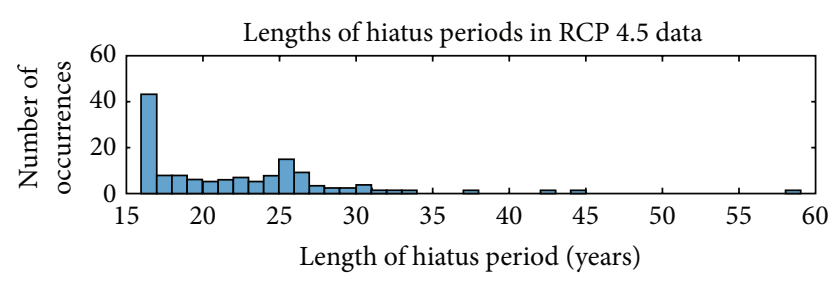

(a)

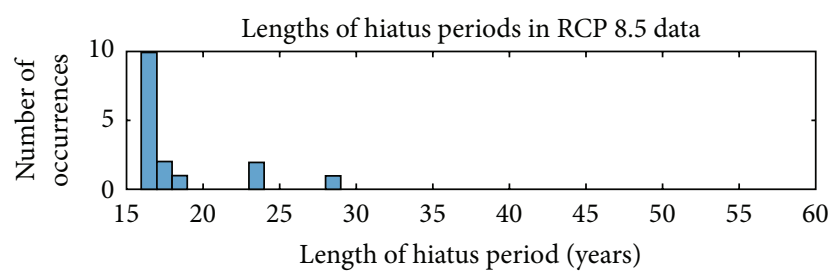

(b)

FIGURE 2: Histograms for the number of hiatus periods detected in all 38 tested CMIP5 models sorted by length in RCP 4.5 (a) and RCP 8.5 (b) for the simulated years 2006-2100.

since the previous 15-year periods do not show a statistically meaningful trend, indicating the 1998-2012 warming hiatus.

The statistical meaningfulness test is applied to the RCP 4.5 GST anomaly data records of all 38 models to detect warming hiatus periods, shown in Figure 4. Every tested model contains 15-year or longer periods in the 21st century which lack a statistically meaningful trend. Since these features statistically resemble the observed 1998-2012 warming hiatus, they are considered evidence of model-simulated warming hiatus periods. The length of these periods tends to be between 15 and 16 years, with over 40 occurrences of hiatus periods of this length across all models (Figure 2). A majority of hiatus periods occur in the first half of the 21st century. Longer hiatus periods were also detected; seven models simulate hiatus periods lasting between 30 and 60 years. These results indicate that warming hiatus periods are a common model feature when operating under the RCP
4.5 experiment. Also of note, several models simulate 15year periods with a statistically significant cooling trend, supporting the Easterling and Wehner [10] study but here using the newer CMIP5 model ensemble.

The statistical meaningfulness test is repeated for the GST anomaly records simulated with the RCP 8.5 experiment. Figure 2 compiles the histogram results of these tests. Only 16 hiatus periods are detected across all models in RCP 8.5 simulations between 2006 and 2100, the majority of which are short in length (between 15 and 16 years) and occur before the year 2050. In 35 out of 38 models, no warming hiatus periods are detected after the year 2050, since every 15 -year period ending after 2050 has a statistically meaningful positive trend (with the exception of the models BCC-CSM1.1.m, MIROC5, and MPI-ESM-LR).

Under the RCP 8.5 scenario, by the mid-21st century the radiative forcing is projected to exceed $5 \mathrm{~W} / \mathrm{m}^{2}$ [1]. The results of this study indicate that most models are unable to simulate warming hiatus periods when operating under accelerated warming conditions resulting from radiative forcing of $5 \mathrm{~W} / \mathrm{m}^{2}$ and higher (a GST increase of $2^{\circ} \mathrm{C}$ ).

The use of monthly time steps, versus annual means, allows for finer distinctions to be made between which periods have statistically meaningful trends and which do not, increasing the possibility of detecting warming hiatus periods. It also allowed for some analysis of seasonal warming. For example, the climate models predict higher GST rates during the winter months (December to February) than the summer months, particularly during RCP 8.5 experiments. This may be due to climate model predictions showing the Arctic to warm much faster than the rest of the world during the winter months, with the greatest temperature anomalies occurring in this region during winter.

Although warming hiatus periods are not detected in most model simulations under the accelerated warming conditions in the RCP 8.5 experiment, it is hypothesized that the climate variations which are associated with warming hiatus periods are still present in these simulations. The next section describes a different statistical approach to detect variations indicative of warming hiatus periods in model data.

2.3. Detecting Rapid Changes in the GST Rate. The rate of change in GST is a measure of climate warming often used to quantify the global-mean climate response to experimental forcing on various timescales (e.g., [1]). In this analysis, the GST rate is computed for the observed warming hiatus and compared with model-simulated GST rates. This analysis differs from the one discussed in Section 2.2 as it provides a different method for identifying climate variations-specifically, rapid GST rate changes-associated with a warming hiatus period, even when a hiatus period is not detected.

To calculate the GST rate, a linear regression is performed on each 15 -year period in monthly time steps. The slope of the line indicates the rate of GST change for that 15-year period, scaled to ${ }^{\circ} \mathrm{C} / \mathrm{dec}$ de. The GST rate is calculated at each time step for GISTEMP GST observations for 15-year periods ending between January 1980 and May 2015, shown in Figure 3. Also shown are the model-mean GST rates using 
RCP 4.5 and RCP 8.5 data up to the year 2100. The GST rate value is plotted corresponding to the final month in the 15 -year time period. Under both experiments, the GST rate remains steady through the first third of the 21st century; thereafter, the rate decreases under RCP 4.5 , while the rate increases and then gradually steadies toward the end of the century under RCP 8.5 .

The 1998-2012 hiatus period corresponds to the sharp decline in the observed GST rate; in Figure 3 the period between May 2007 and May 2012 represents the fastest five-year decrease in GST rate during the observed hiatus (highlighted in gray), accounting for most of the total decrease during the hiatus. Over this five-year period, the GST rate decreased by about $.24^{\circ} \mathrm{C} /$ decade. To evaluate the possibility that models operating under accelerated warming experiments can produce similar rapid changes in GST, RCP 8.5 data from all 38 models are examined for 5 -year changes in GST rate that are equal to or greater than $.24^{\circ} \mathrm{C} /$ decade. Of the 38 tested models, 23 models produce at least one period during the 21st century in which the magnitude of the GST rate change was equal to or greater than the observed 2007-2012 GST rate change. The GST rates of these models are plotted in Figure 5, and GST rate changes which are equal to or greater than $.24^{\circ} \mathrm{C} /$ decade are marked red. Because rapid changes in the GST rate are found in a majority of the models (23 out of 38), this variability appears to be a common feature in the model simulations under accelerated warming conditions.

Interestingly, it should also be noted in Figure 3 that the annual cycle appears in the computed GST rates in RCP 4.5 and 8.5 anomaly data, despite having been removed by subtracting the 1951-1980 climatology. It appears that the annual cycle of GST becomes amplified under warming experiments, as the amplitude of this cycle increases toward the end of the 21st century.

\section{Results and Discussion}

This study provides further evidence that the recent hiatus in GST warming can be reproduced using CMIP5 model simulation data operating under accelerated warming experiments. This is done by analyzing data from 38 model simulations of climate response to changing greenhouse gas levels throughout the 21st century using two different increased radiative forcing experiments. The first step of the analysis (Section 2.2) consists of testing trends in the modeled GST data records for statistical meaningfulness in which any 15-year or longer period showing a nonsignificant trend would indicate a warming hiatus. All tested models are able to produce warming hiatus periods under the RCP 4.5 experiment. Since early 21 st-century GST rates under RCP 4.5 are close to present-day rates, this suggests that the hiatus observed recently resulted from a short-term period of variability which was strong enough to dampen the anthropogenic warming signal. However, once future climate warming exceeds conditions corresponding to $5 \mathrm{~W} / \mathrm{m}^{2}$ radiative forcing in the RCP 8.5 experiment- $\mathrm{a} 2^{\circ} \mathrm{C}$ GST rise, after the year 2050-most tested models simulate only statistically significant positive warming trends with no warming hiatus periods.

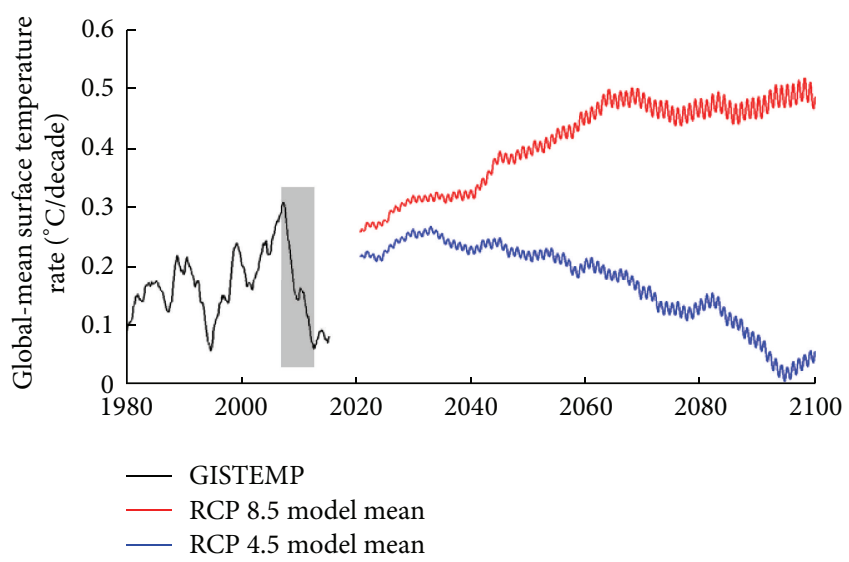

FIGURE 3: GST rates $\left({ }^{\circ} \mathrm{C} /\right.$ decade $)$ of 15 -year periods ending between January 1980 and May 2015 for GISTEMP and 15-year periods ending between December 2020 and December 2099 for RCP 4.5 and RCP 8.5 data, relative to 1951-1980 climatology using the Historical experiment. The lines corresponding to the RCP data are the mean rates of all 38 models for that experiment.

To test whether the variations associated with the warming hiatus are still present in models in the RCP 8.5 simulations after the year 2050, the second step of the analysis (Section 2.3) is performed which detects variations in the GST rate that are consistent with the observed rapid change during the $1998-2012$ hiatus period. The GST rate is calculated for each modeled GST record to detect fluctuations which are equal to or greater than the magnitude of the strongest observed GST rate change $\left(.24^{\circ} \mathrm{C} /\right.$ decade $)$. In 23 out of 38 models, periods with a rapid GST rate change are identified. Fourteen of these models simulate rapid GST rate changes after the year 2050 in the RCP 8.5 experiment (Figure 5). This result demonstrates that many of the models produce variations consistent with the observed warming hiatus, even under accelerated warming caused by radiative forcing of $5 \mathrm{~W} / \mathrm{m}^{2}$ and higher. The combined results of the first and second analyses show that models-under accelerated warming conditions-simulate variability which resembles the observed warming hiatus, even when warming hiatus periods are not produced.

The present study does not identify the specific factors responsible for the warming hiatus; however, it does suggest that such factors contributing to the observed variability are present in CMIP5 climate models, which are able to simulate periods resembling the warming hiatus and create similar fluctuations in GST rate under the tested experimental conditions.

\section{Conclusions}

In conclusion, this study finds evidence of warming hiatus periods in climate model simulations of GST through a statistical comparison between the 1998-2012 observed global warming hiatus and model simulations. This study uses the largest set of climate model simulation data from CMIP5 to perform the analyses-including 38 models and simulation data from two different warming experimentscompared to the previous literature. It finds evidence that 


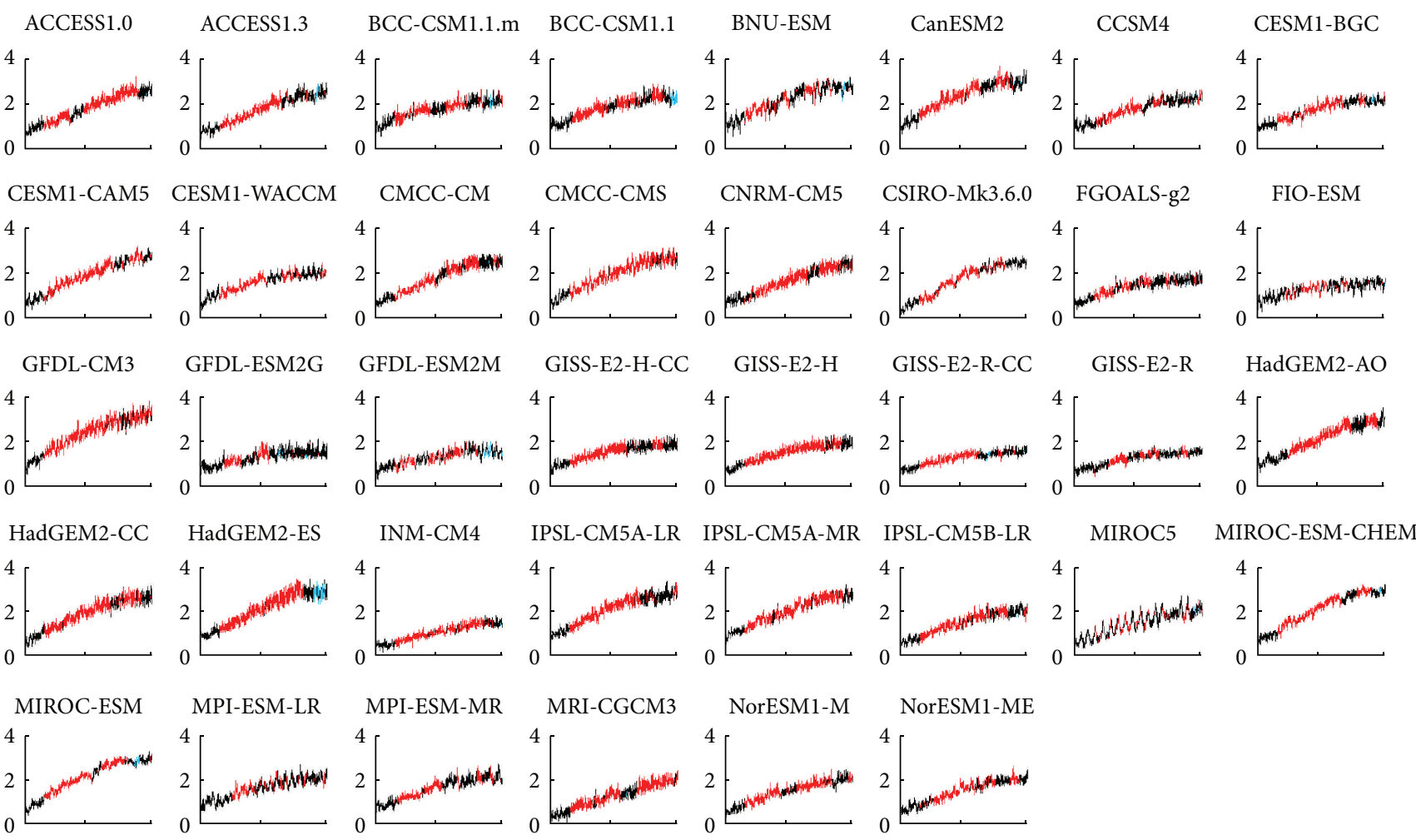

FIGURE 4: Global-mean surface temperature (GST) anomalies in ${ }^{\circ} \mathrm{C}$ (ordinate) from January 2006 to December 2100 (abscissa) relative to the 1951-1980 climatology from the Historical experiment for each tested model using RCP 4.5. Statistically meaningful trend periods are marked as described in Figure 1.

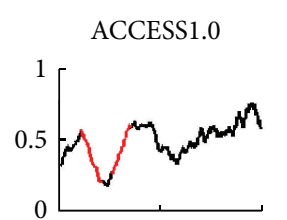

CESM1-WACCM

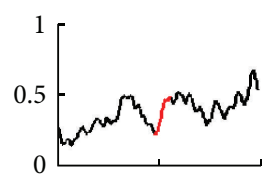

$$
\text { HadGEM2-CC }
$$
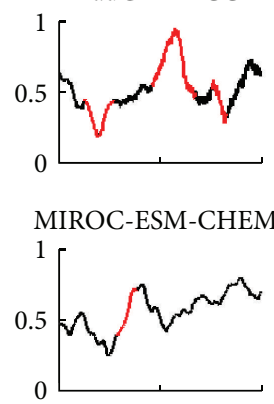

ACCESS1.3

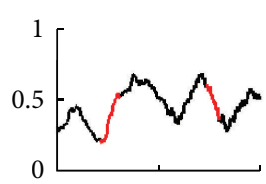

CMCC-CM

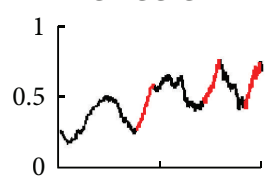

HadGEM2-ES
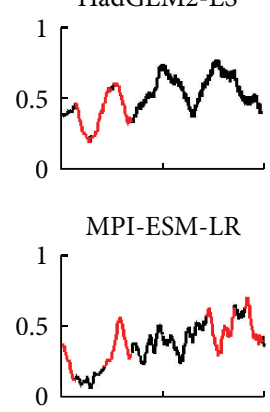

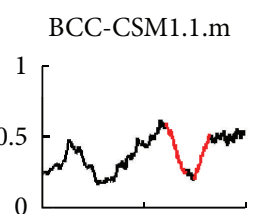

CMCC-CMS

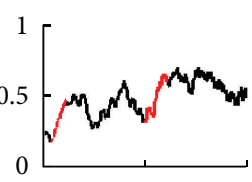

IPSL-CM5A-LR
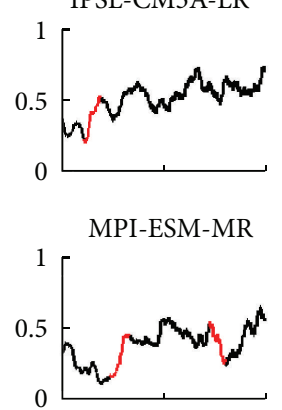

BNU-ESM

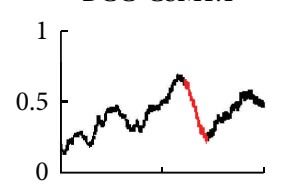

CSIRO-Mk3.6.0

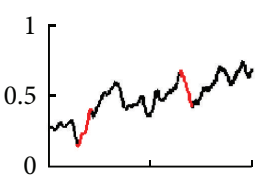

IPSL-CM5A-MR
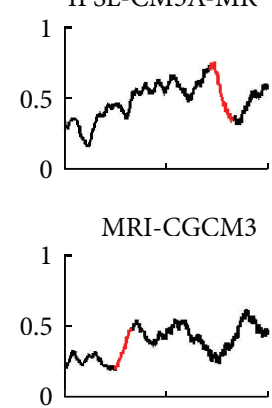

CanESM2

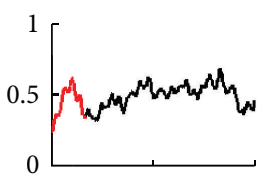

GFDL-ESM2M

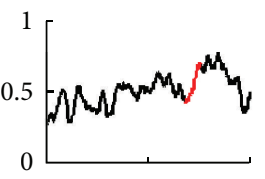

HadGEM2-AO

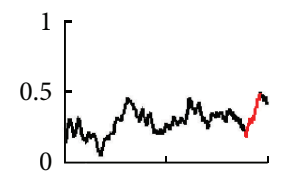

IPSL-CM5B-LR
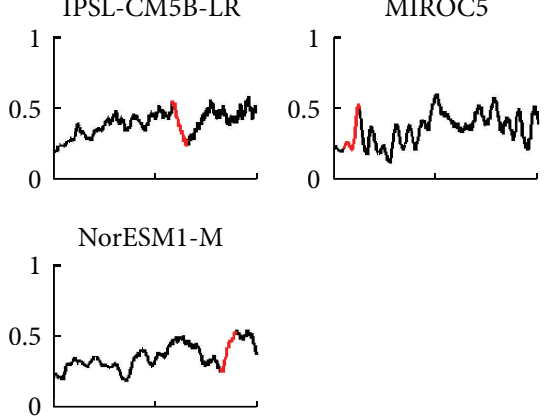

FIGURE 5: GST rate in ${ }^{\circ} \mathrm{C} /$ decade (ordinate) for the 23 models which produce 5-year or longer periods of GST rate equal to or greater than the highest observed GST rate change during the observed 1998-2012 hiatus, marked in red, over the period December 2020 to December 2100 (abscissa). 
the models produce GST rate changes that are consistent with those observed during the 1998-2012 hiatus period, even when hiatus periods are not simulated. The study supports the hypothesis that the 1998-2012 hiatus period was caused by variations which are reproducible in climate model experiments which simulate increasing radiative forcing. This study also shows that most models are unable to simulate hiatus periods once the GST increase exceeds $2^{\circ} \mathrm{C}$.

\section{Competing Interests}

The authors declare that they have no competing interests.

\section{Acknowledgments}

This study was made possible through the NASA Internships, Fellowships, and Scholarships (NIFS) Program with resources and support provided by Charles R. Trepte, Patrick C. Taylor, and the NASA Langley Research Center. The authors are grateful for helpful comments from Tobias Wegner. GISTEMP data is publicly available online and was obtained from http://data.giss.nasa.gov/gistemp/ in July 2015. CMIP5 model output was downloaded from the archive data portal at https://pcmdi.llnl.gov/projects/cmip5/.

\section{References}

[1] T. F. Stocker, D. Qin, G.-K. Plattner et al., Eds., Climate Change 2013: The Physical Science Basis. Contribution of Working Group I to the Fifth Assessment Report of the Intergovernmental Panel on Climate Change, Cambridge University Press, Cambridge, UK, 2013.

[2] R. K. Kaufmann, H. Kauppi, M. L. Mann, and J. H. Stock, "Reconciling anthropogenic climate change with observed temperature 1998-2008," Proceedings of the National Academy of Sciences of the United States of America, vol. 108, no. 29, pp. 11790-11793, 2011.

[3] S. Solomon, K. H. Rosenlof, R. W. Portmann et al., "Contributions of stratospheric water vapor to decadal changes in the rate of global warming," Science, vol. 327, no. 5970, pp. 1219-1223, 2010.

[4] S. Solomon, J. S. Daniel, R. R. Neely III, J.-P. Vernier, E. G. Dutton, and L. W. Thomason, "The persistently variable 'background' stratospheric aerosol layer and global climate change," Science, vol. 333, no. 6044, pp. 866-870, 2011.

[5] K. E. Trenberth, "An imperative for climate change planning: tracking Earth's global energy," Current Opinion in Environmental Sustainability, vol. 1, no. 1, pp. 19-27, 2009.

[6] K. E. Trenberth and J. T. Fasullo, "An apparent hiatus in global warming?” Earth's Future, vol. 1, no. 1, pp. 19-32, 2013.

[7] X. Chen and K.-K. Tung, "Varying planetary heat sink led to global-warming slowdown and acceleration," Science, vol. 345, no. 6199, pp. 897-903, 2014.

[8] J. Vialard, "Ocean science: hiatus heat in the Indian Ocean," Nature Geoscience, vol. 8, no. 6, pp. 423-424, 2015.

[9] G. A. Meehl, A. Hu, J. M. Arblaster, J. Fasullo, and K. E. Trenberth, "Externally forced and internally generated decadal climate variability associated with the interdecadal pacific oscillation," Journal of Climate, vol. 26, no. 18, pp. 7298-7310, 2013.
[10] D. R. Easterling and M. F. Wehner, "Is the climate warming or cooling?" Geophysical Research Letters, vol. 36, no. 8, Article ID L08706, 2009.

[11] C. D. Roberts, M. D. Palmer, D. McNeall, and M. Collins, "Quantifying the likelihood of a continued hiatus in global warming," Nature Climate Change, vol. 5, no. 4, pp. 337-342, 2015.

[12] K. E. Taylor, R. J. Stouffer, and G. A. Meehl, "An overview of CMIP5 and the experiment design," Bulletin of the American Meteorological Society, vol. 93, no. 4, pp. 485-498, 2012.

[13] A. C. Bryhn and P. H. Dimberg, "An operational definition of a statistically meaningful trend," PLoS ONE, vol. 6, no. 4, Article ID e19241, 2011.

[14] J. Hansen, R. Ruedy, M. Sato, and K. Lo, "Global surface temperature change," Reviews of Geophysics, vol. 48, no. 4, Article ID RG4004, 2010. 

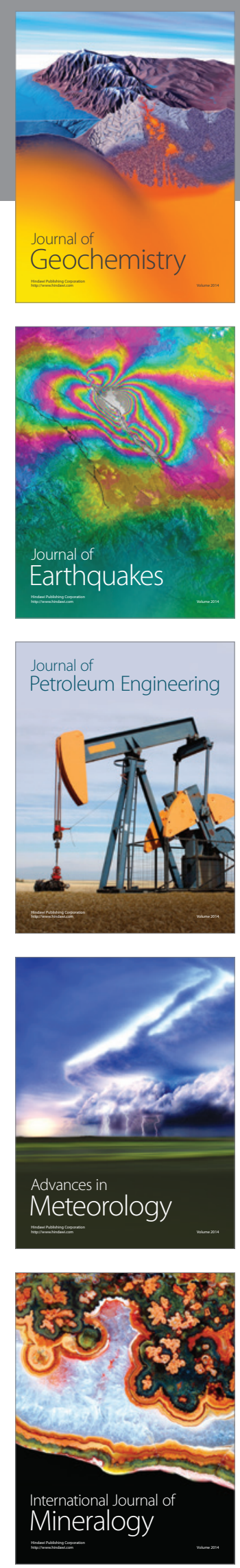
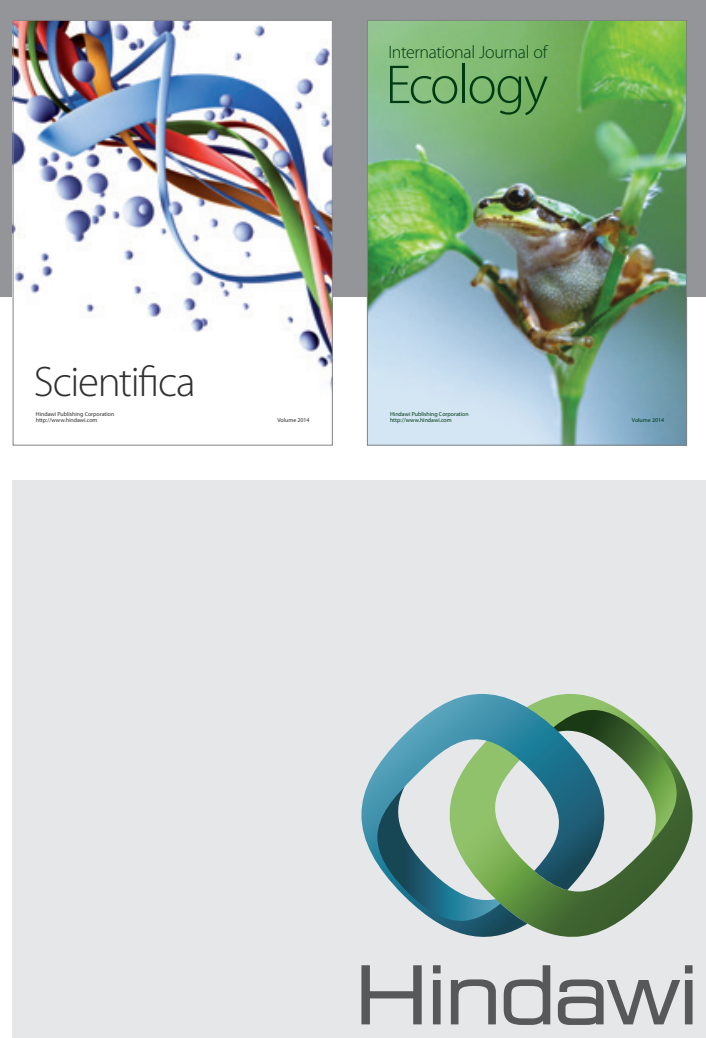

Submit your manuscripts at

http://www.hindawi.com
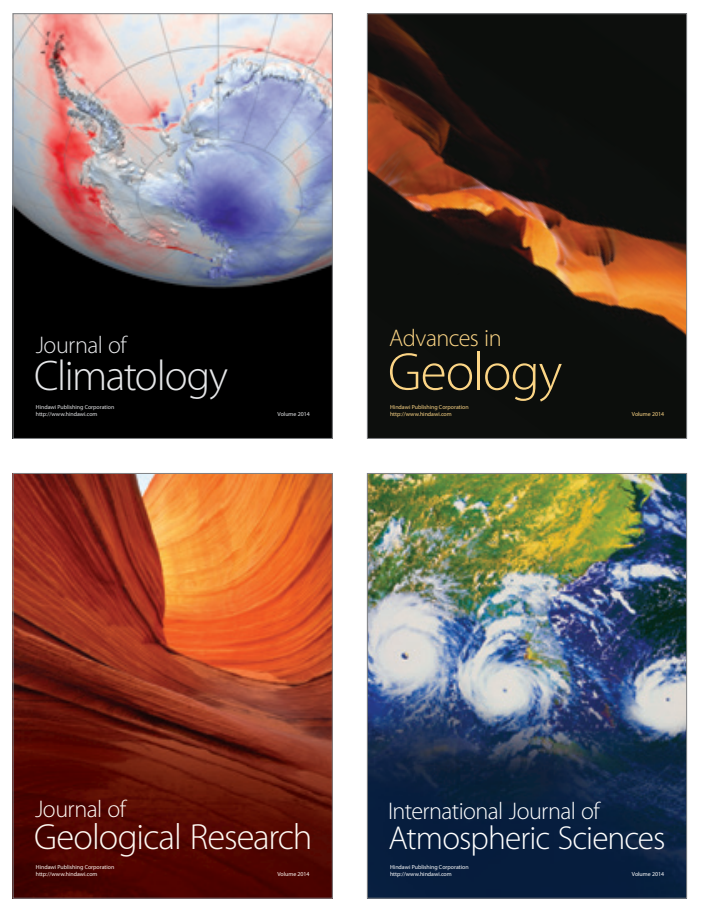

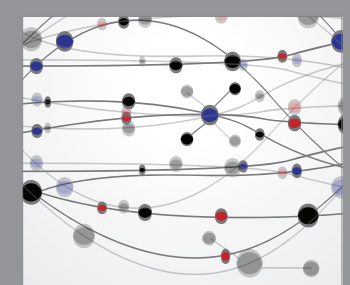

The Scientific

\section{World Journal}
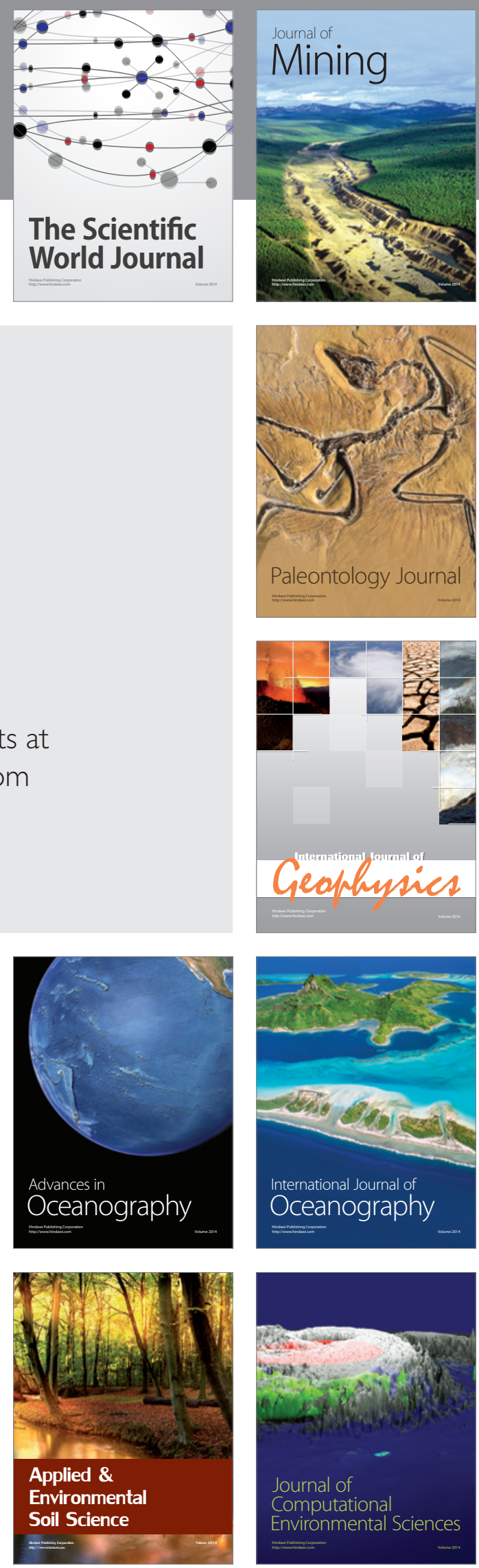